\title{
A system-wide approach to minimize the operational cost of bench production in open-cast mining operations
}

\author{
Burak Ozdemir $^{1}$ (i) Mustafa Kumral $^{1}$ (i)
}

Received: 13 August 2018/Revised: 2 October 2018/Accepted: 4 December 2018/Published online: 12 December 2018

(C) The Author(s) 2018

\begin{abstract}
The production cycle of open-cast coal mines generally includes drilling, blasting, loading, hauling and coal preparation activities. Individual optimization of these activities does not mean that the whole system is optimized. This paper proposes a cost model considering all activities in mining cycle and system-wide approach to minimize the total mining cost of bench production. Since the fragmentation size and blast-hole diameter are linked to all activities of mining system, they are considered as decision variables in the problem formulation. The operation costs are then minimized by using the evolutionary algorithm. Moreover, the impact of the change in the explosive price, and the hourly unit cost of equipment on total mining cost is quantified by sensitivity analysis. A case study is implemented to demonstrate the developed model.
\end{abstract}

Keywords Mine production cycle $\cdot$ Rock fragmentation $\cdot$ Cost optimization $\cdot$ Evolutionary algorithm $\cdot$ Sensitivity analysis

$\begin{array}{ll}\text { List of symbols } \\ A & \text { Rock factor } \\ B & \text { Burden } \\ C_{B} & \text { Blasting cost } \\ C_{C} & \text { Crushing cost } \\ C_{D} & \text { Drilling cost } \\ c_{D} & \text { Unit cost of the drilling machine } \\ C_{H} & \text { Hauling cost } \\ C_{L} & \text { Loading cost } \\ c_{L} & \text { Unit cost of the loader } \\ C_{M} & \text { Total mining cost of a bench } \\ c_{T} & \text { Unit cost of the truck } \\ D & \text { Hole diameter } \\ F & \text { Fill factor } \\ H & \text { Bench height } \\ J & \text { Sub-drill } \\ K_{2} & \text { Crusher circuit constant }\end{array}$

Mustafa Kumral

mustafa.kumral@mcgill.ca

1 Department of Mining and Materials Engineering, McGill University, 3450 University Street, Montreal, QC H3A 0E8, Canada
$L \quad$ Bench length

$M_{i c} \quad$ Crushing work index

$n \quad$ Blast geometry constant

$N \quad$ Number of blast hole

$P_{50} \quad$ Mean fragmentation size

$P_{80} \quad 80 \%$ passing size

$p_{e} \quad$ Price of ANFO

$P_{\text {max }}$ Maximum particle size

$Q_{e} \quad$ Required amount of ANFO

$R \quad$ Maximum allowable feed size of crusher

$r_{D} \quad$ Drill rate

$S \quad$ Spacing

$S_{e} \quad$ Relative weight strength of explosive to ANFO

$t_{c} \quad$ Truck cycle time

THT Total hauling time

$t_{l} \quad$ Loading time

TLT Total loading time

$T_{S} \quad$ Shovel bucket capacity (tonne)

$T_{T} \quad$ Truck capacity (tonne)

$u \quad$ Energy price

$V_{0} \quad$ Volume of the rock

$V_{S} \quad$ Shovel bucket capacity $\left(\mathrm{m}^{3}\right)$

$V_{T} \quad$ Truck capacity $\left(\mathrm{m}^{3}\right)$ 
W Bench width

$W_{c} \quad$ Specific energy

$x_{1} \quad$ Crusher feed size

$x_{2} \quad$ Crusher product size

$\rho_{e} \quad$ Bulk density of explosive

$\rho_{r} \quad$ Bulk density of rock

\section{Introduction}

Mining companies are usually price-takers. Therefore, they do not have much power to set the price which is highly volatile in an unpredictable manner. Unfortunately, the mining industry has no universally accepted tools to predict the price direction and its fluctuations. The past evolution of price and transactions in the future markets provide very limited control over the prices. As a result, the mining companies concentrate on finding efficient cost reduction approaches as well as the price prediction/control. One way to reduce the costs is to invest in new technologies. However, the investment in new technologies may not always be secure, at least in short-term. For example, sufficient financial resources or skills may not be available. Hence, the focus inevitable becomes how to improve operations in such a way as to take cost advantages.

In an open-cast mining operation, the production cycle comprises drilling, blasting, loading, hauling and coal preparation subsystems. Significant cost savings can be achieved by minimizing the cost of these activities (Kozan and Liu 2017). However, optimizing a single subsystem does not mean that the whole system is optimized. To optimize entire system for more cost-efficient operations, a system engineering approach is required. The systematic approach should be used to identify and evaluate the designs of engineering systems.

Although each of these activities includes various cost elements, rock fragmentation size affects the cost of all activities (Fisonga et al. 2017). The relationship between rock fragmentation and the cost of the mining subsystems is given in Fig. 1 (Nielsen 1983). The particle size obtained through rock fragmentation affects loading, hauling and crushing performance. Higher rock fragmentation means higher drilling and blasting costs. However, increasing fragmentation provides more cost-effective loading and hauling cycles. Similarly, the crushing cost is likely to decrease with decreasing feed size. More information about the production activities can be found at Chugh and Behum (2014).

\subsection{Drilling and blasting}

The performance of drilling and blasting (rock fragmentation) is measured by fragmented space and particle size distribution of fragmented material. The particle size distribution is a function of the blast design and the specific explosive charge of each hole (Ouchterlony et al. 2017). Blasting design parameters (such as bench height, burden, spacing, explosive charge, etc.) affect the rock fragmentation size. Particle size of blasted material (1) increases if
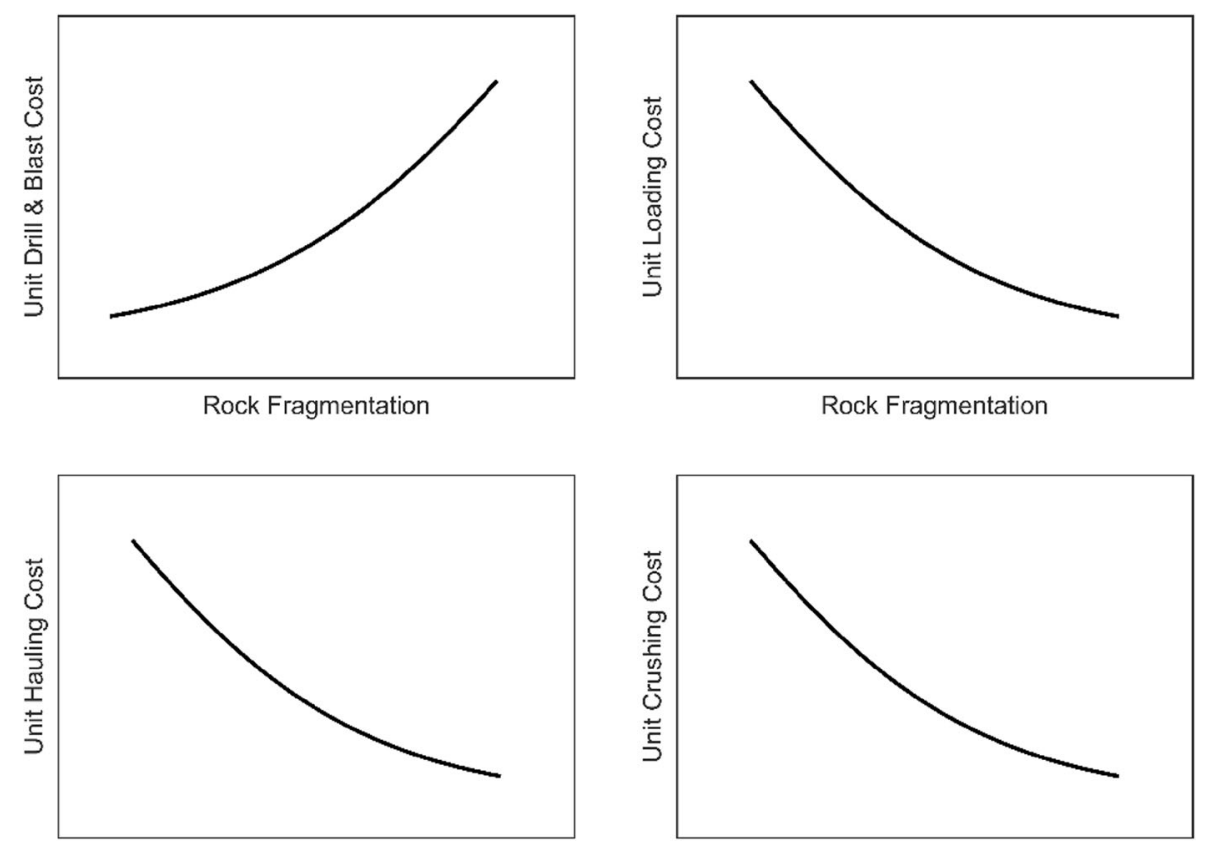

Rock Fragmentation

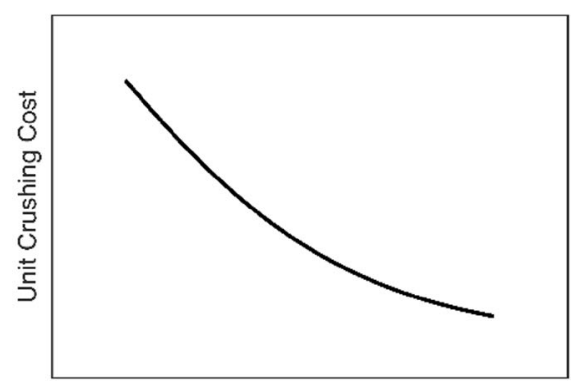

Rock Fragmentation

Fig. 1 The relationship between rock fragmentation and the cost of the mining activities 
the burden to hole diameter ratio increases, (2) decreases if the spacing to burden ratio increases, (3) increases if stemming length to burden ratio increases, (4) decreases with the increase in explosive charge, and (5) decreases if bench height to burden ratio increases (Singh et al. 2016). The effect of drilling and blasting geometry on particle size distribution can be estimated by using mathematical modelling (Kecojevic and Komljenovic 2007).

Since the cost of all mining activities consists of the fragmentation size, the mining cost can be minimized by optimizing the mean particle size after blasting. Moreover, the blast design parameters change depending on the drill hole diameter, and the blast design parameters determine the drilling and blasting cost. Therefore, drill hole diameter is the other key factor in the calculation of drilling and blasting cost. These two factors can be used as the decision variable in the optimization problem as they can be modified during the mining operation. The blast pattern can be altered for different blasts in the same operation. Moreover, the hole diameter can also be changed by changing the size of the bit as soon as the bit is compatible with the drilling machine.

\subsection{Loading and hauling}

The optimization of loading subsystems is crucial to minimize the total mining cost. The productivity of loaders is affected by the characteristics of muck piles such as angle of repose, looseness, particle size distribution and moisture content (Singh and Narendrula 2006). Inefficient blasting causes lower productivity for shovels. The looseness of the blasted material has a direct relationship with the mean particle size and the index of uniformity; hence, the bucket fill factor is affected by the looseness. Higher bucket fill factor value is favorable for the production and is obtained by the decreasing particle size of the material. The looseness and angle of repose of the muck pile affect swing time. The optimal muck pile design provides shorter swing time which leads to more cost-efficient loading. Furthermore, the moisture content of the muck pile has an impact on the angle of repose and stickiness of the material.

Osanloo and Hekmat (2005) investigated the relationship between particle size of the blasted material and shovel productivity in a surface mine based on RosinRammler-Bennett expression. It is concluded that $50 \%$ increase in particle size causes $20 \%$ loss in shovel productivity. Moreover, Bogunovic and Kecojevic (2011) quantified the impact of bucket fill factor on the shovel production and energy consumption. Furthermore, the efficiency and cost of mining activities are also related to the rock mass mechanical parameters such as RQD, compression strength, joints, discontinuities, etc. The quality, particle size distribution, swell factor and the geometry of the blasted material influence the efficiency of loading and hauling activities (Taherkhani and Doostmohammadi 2015).

Hauling is another mining activity needed to be optimized for mining cost minimization. The production rate and cost of hauling are substantially influenced by the magnitude of the payloads of the trucks (Dickerson et al. 1986) which highly depends on a fill factor decided by the particle size of the blasted material. Lower fragmentation size results in higher fill factor and higher production rate for the trucks. However, when weight capacity of the trucks is reached, production rate remains constant even if fragmentation size decreases. In this case, unnecessary fragmentation causes an increase in unit cost of drilling and blasting. If the bulk density of the loaded material is small, the lowering the fragmentation size can be considered to increase the truck's production. Otherwise, the weight limit of the trucks does not allow to increase production even though the fragmentation size decreases.

\subsection{Crushing}

The impact of blasting on crushing and grinding was also investigated in mining literature (Workman and Eloranta 2003). Drilling and blasting operation determined the particle size of the crusher feed. Since more energy required to break coarser feed size (Pothina et al. 2007), smaller fragmentation size can provide substantial cost savings for the crushing process by reducing the energy consumption. However, decreasing particle size causes an increase in the production as more material is loaded and hauled in a cycle. In this case, the production capacity of crusher may be exceeded which leads to a queue at the crusher and the opportunity costs for the hauling and loading equipment.

Because of the abovementioned impacts of the blasting on the other mining subsystems, its optimization is crucial in an open-cast mining operation. This optimization can be achieved by using different techniques such as genetic algorithm (Monjezi et al. 2011), manual simulation model (Neale 2010) or particle swarm algorithm (AminShokravi et al. 2017), etc. Testing different blast patterns and evaluating their results on drilling and blasting costs can be another alternative for the drill and blast optimization (Kahriman and Ceylanoalu 1996; Martin 2006).

In mining literature, most of the research focused on optimizing mining subsystems individually. In such an approach, the cost can convey to the subsequent subsystems. In other words, while the cost of one subsystem is minimized, the cost of following subsystems may increase. In fact, focusing on an individual subsystem may cause missing the relationship between the subsystems. This paper proposes a novel system-wide approach to optimize 
the mining cost by considering the relationship among interrelated subsystems. Since the costs of activities forming mining cycle are expressed regarding fragmentation size to be obtained and blast-hole diameter, these two parameters are used as common ground in the calculations. Once the optimum fragmentation size is obtained, the other sections of a specific mining subsystem (such as the size of the mining equipment, number of trucks, flow rate, etc.) can be optimized individually. Moreover, the approach includes a sensitivity analysis to quantify the relative effect of the cost components.

The sum of optimal sub-systems does not create an optimal for the system. In this paper, the costs of activities forming mining cycle are expressed regarding fragmentation size to be obtained and blast-hole diameter.

\section{Methodology}

\subsection{Cost analysis}

Mining production system consists of drilling, blasting, loading, hauling and crushing subsystems. The mean fragmentation size is related to the cost of all subsystems. To minimize the mining cost, the relation between the mean fragmentation size and the cost of each activity should be analyzed.

The total mining cost of a bench $\left(C_{M}\right)$, consists of drilling, blasting, loading, hauling and crushing costs, and is calculated by Eq. (1).

$C_{M}=C_{D}+C_{B}+C_{L}+C_{H}+C_{C}$

where $C_{D}$ is the drilling cost (\$), $C_{B}$ is blasting cost (\$), $C_{L}$ is the loading cost $(\$), C_{H}$ is hauling cost $(\$)$, and $C_{C}$ is crushing cost for crusher $(\$)$.

\subsubsection{Drilling cost}

The drilling cost depends on bench configuration, the performance of drilling equipment, rock characteristics and blasting pattern. Typical mining bench is illustrated in Fig. 2. In a bench blasting activity, the length, width, and height of the bench are known while designing a blast. Besides, other parameters such as burden, spacing, and sub-drilling are decided based on the hole diameter.

The burden is calculated by the following equation (Konya 1983).

$B=0.03780 \times D \times\left(\frac{\rho_{e}}{\rho_{r}}\right)^{0.333}$

where $B$ is the burden ( $\mathrm{m}), D$ is the hole diameter $(\mathrm{mm}), \rho_{e}$ is the bulk density of explosive (tonne $/ \mathrm{m}^{3}$ ) and $\rho_{r}$ is the bulk density of the rock (tonne/ $\mathrm{m}^{3}$ ). When the burden is known, the spacing is found by Eq. (3) (Konya 1983).

$S= \begin{cases}0.125 \times H+0.875 \times B & \text { if } H<4 B \\ 1.4 \times B & \text { if } H>4 B\end{cases}$

where $S$ is the spacing $(\mathrm{m})$ and $H$ is the bench height (m). Moreover, sub-drilling $J$ is equal to (Konya 1983):

$J=0.3 \times B$

Drilling cost is directly related to the total length of the drilled hole. The total length of a hole is the bench height $(H)$ and sub-drilling $(J)$. The total length of a hole is multiplied with the number of drill holes $(N)$ to find the total drilled length. Given average drill rate $\left(r_{D}\right),(\mathrm{m} / \mathrm{h})$ and the hourly operation cost $\left(c_{D}\right)$ of drilling machine, the drilling cost of the bench is calculated by the following equation.

$C_{D}=\frac{(H+J) \times N}{r_{D}} \times c_{D}$

where $N$ is the number of drill holes in the blasting bench which is based on the burden, spacing, bench width and bench length distances.

\subsubsection{Blasting cost}

Explosive expenditure covers the main part of the blasting cost. Since the fixed costs of blasting (such as detonating cords, boosters, detonators, labor, etc.) do not affect rock fragmentation, they are ignored. The relation between the rock fragmentation and the required explosive amount is expressed by Eq. (6) (Kuznetsov 1973).

$P_{50}=A \times\left(\frac{V_{0}}{Q_{e}}\right)^{0.8} \times Q_{e}^{1 / 6}$

where $P_{50}$ is the mean fragment size $(\mathrm{cm}), A$ is the rock factor, $V_{0}$ is the volume of the rock per blast hole $\left(\mathrm{m}^{3}\right), Q_{e}$ is the mass of TNT containing the energy equivalent of the explosive charge in each blast hole $(\mathrm{kg}) . A$ is 7 for medium hard rocks, 10 for hard but highly fissured rocks and 13 for very hard, weakly fissured rocks. Alternatively, the mean fragmentation size can be estimated by using neural networks (Kulatilake et al. 2010), Monte Carlo simulation modeling (Morin and Ficarazzo 2006) or multiple regression modeling (Faramarzi et al. 2013). The volume of the rock is equal to:

$V_{0}=B \times S \times H$

The explosive type used in the Eq. (6) is TNT; however, it can be reformulated depending on the explosive type as given in Eq. (8) (Gheibie et al. 2009). 


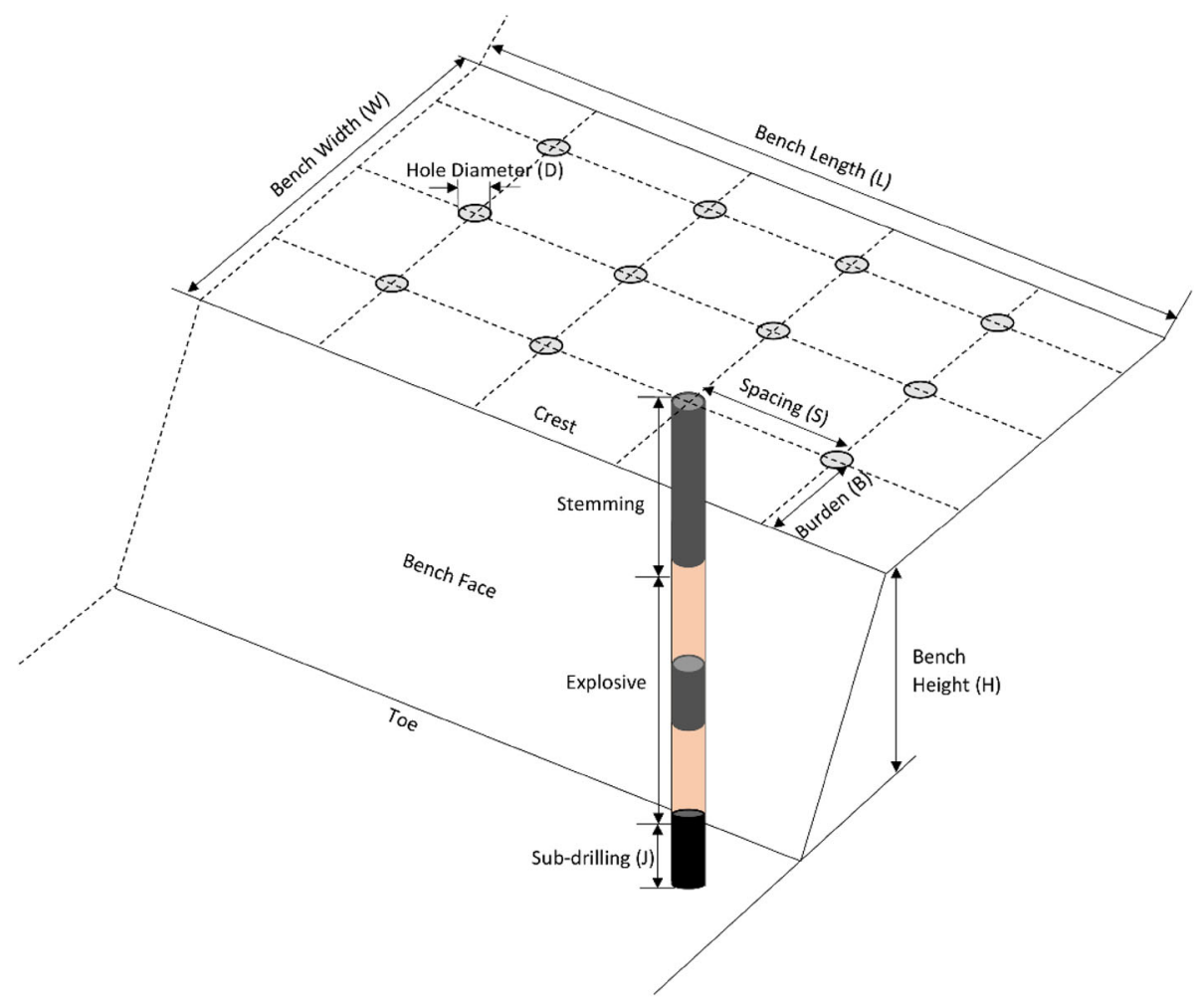

Fig. 2 Illustration of a mining bench

$P_{50}=A \times\left(\frac{V_{0}}{Q_{e}}\right)^{0.8} \times Q_{e}^{1 / 6}\left(\frac{S_{e}}{115}\right)^{-19 / 30}$

where $S_{e}$ is the relative weight strength of the explosive according to ANFO. The Eq. (8) can be rewritten for $Q_{e}$ as shown below.

$Q_{e}=\frac{115 \times A^{30 / 19} \times V_{0}^{24 / 19}}{P_{50 / 19}^{30} \times S_{e}}$

Once the required amount of the explosive for each hole is obtained, the blasting cost of the bench is calculated as follows.

$C_{B}=Q_{e} \times p_{e} \times N$

where $p_{e}$ is the price of the explosive $(\$ / \mathrm{kg})$.

\subsubsection{Loading cost}

The cost of loading is related to the material movement in each load. Although the loader bucket has a certain volume capacity, it is not possible to utilize all the capacity in a real operation because of the space between the particles. There is a fill factor of the bucket volume depending on particle size distribution. The fill factor is simply the ratio of the volume of loaded material to the capacity of the bucket. If the particle size increases, the space between the particles increases and the fill factor decreases. Decreasing amount of the material in each load means a decrease in the loading efficiency. On the other hand, if the rock is well fragmented, the fill factor and the loading efficiency will be high. The relation between the fill factor and the mean fragmentation size can be found by the regression analysis.

Given fill factor $(F)$, the total loading time of the material in the blasted bench is calculated by Eq. (11).

$T L T=\frac{V_{0} \times N}{V_{S} \times F} \times t_{l}$

where $V_{S}$ is the bucket capacity of the shovel $\left(\mathrm{m}^{3}\right)$ and $t_{l}$ is the swing time for one load. Once total loading time is obtained, the loading cost $\left(C_{L}\right)$ is found by Eq. (12).

$C_{L}=\frac{V_{0} \times N}{V_{S} \times F} \times t_{l} \times c_{L}$

where $c_{L}$ is the operating cost of the loader $(\$ / \mathrm{h})$.

\subsubsection{Hauling cost}

Similar to the loading cost, the fill factor is one of the major components of hauling cost. The relation between rock fragmentation and the hauling cost is quantified by the fill factor. To maintain efficient loading operation, higher fill factor is preferable. The total time required for hauling the 
blasted material from the bench to its destination is calculated by Eq. (13).

$T H T=\frac{V_{0} \times N}{V_{T} \times F} \times t_{c}$

where $V_{T}$ is the heaped capacity of the truck $\left(\mathrm{m}^{3}\right)$ and $t_{c}$ is the cycle time of the trucks. When the total hauling time is known, the hauling cost of material within a bench is obtained by Eq. (14).

$C_{H}=T H T \times c_{T}$

where $c_{T}$ is the operating cost of the truck $(\$ / \mathrm{h})$.

\subsubsection{Crushing cost}

As crushing is the last chain of interrelated subsystems affected by mean fragmentation size, it should be included in the cost analysis. Crusher cost varies with the particle size of the feed. The crushing cost is calculated based on specific energy. The energy requirement increases when the particle size of the material increases. Specific energy for conventional crushers is obtained by Eq. (15) (Morrell 2009).

$W_{c}=K_{2} \times M_{i c} \times 4 \times\left(x_{2}^{f\left(x_{2}\right)}-x_{1}^{f\left(x_{1}\right)}\right)$

where $W_{c}$ is the specific energy ( $\mathrm{kWh} /$ tonne), $x_{1}$ is the $80 \%$ passing size for the feed $(\mu \mathrm{m}), x_{2}$ is the $80 \%$ passing size $\left(P_{80}\right)$ for the product of the crusher $(\mu \mathrm{m}), M_{i c}$ is crushing work index which is $7.2 \mathrm{kWh} / \mathrm{t}$ for conventional crushers.
$K_{2}$ is a crusher system constant which is taken 1.0 if crusher is operated in a closed circuit with a classifying screen and 1.19 if crusher is working in an open circuit. Also, $f$ is a function of particle size and calculated by the following equation (Morrell 2009).

$f\left(x_{j}\right)=-\left(295+x_{j} / 1000000\right)$

In a bench blasting, the fragmentation size is not constant for all particles because of the heterogeneity of rock formation. The parameters of the distribution are obtained by sieving analysis or image analysis. Typically, it shows a cumulative distribution as given in Fig. 3. Mean fragmentation size $\left(P_{50}\right)$ is the sieve interval in which $50 \%$ of the material passes. Similarly, $P_{80}$ is the sieve interval which $80 \%$ of the material passes and derived by the Rosin-Rammler particle size distribution function which is given below (Vesilind 1980).

$P(x)=1-e^{-\ln (2)\left(x / P_{50}\right)^{n}}$

where $n$ is the material uniformity constant depending on blast geometry and rock mass. More information about the fragment size distribution in a bench blasting can be found at (Cho et al. 2003).

The crushing cost is found by:

$C_{C}=W_{c} \times u \times V_{0} \times N \times \rho_{r}$

where $u$ is the energy price $(\$ / \mathrm{kWh})$.

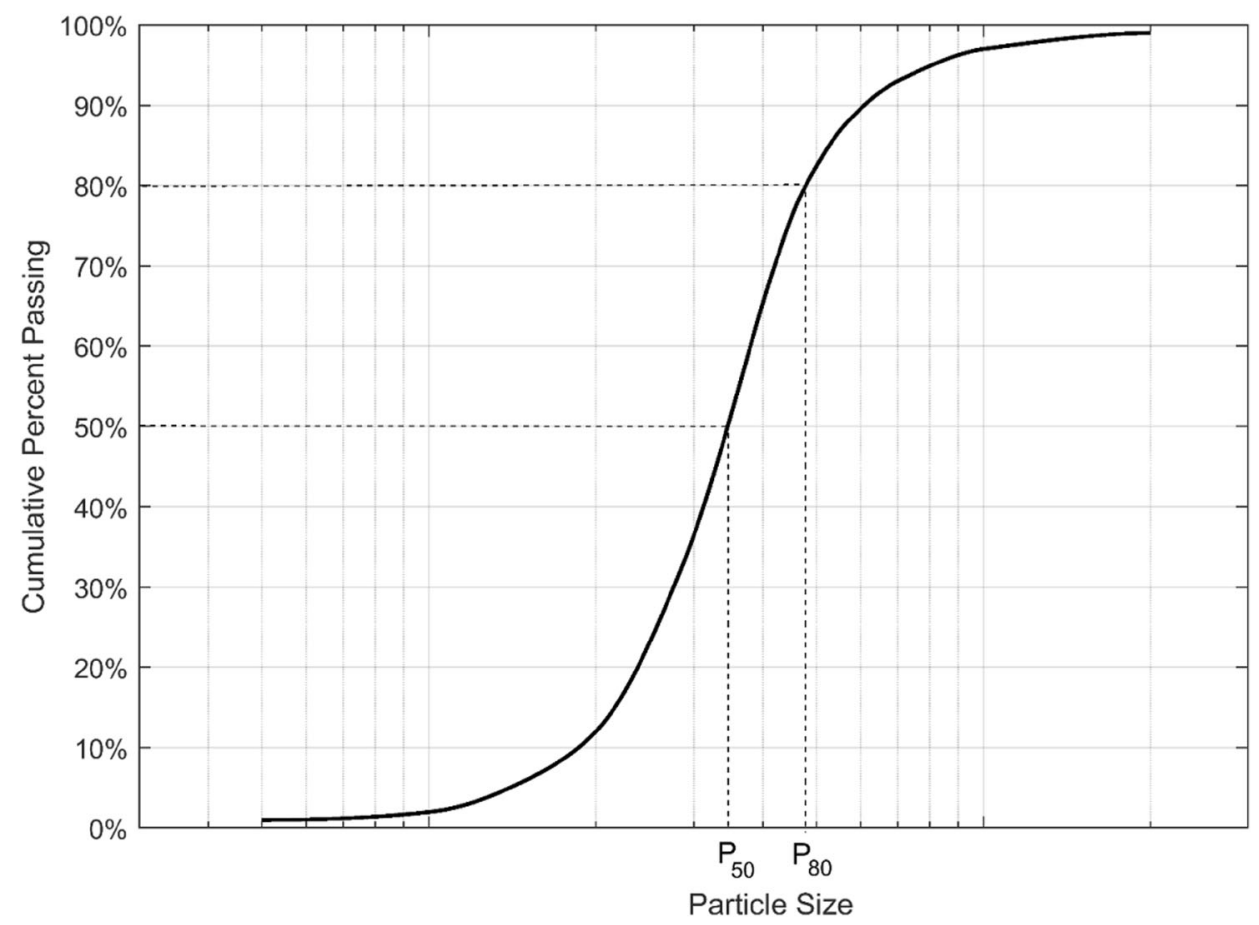

Fig. 3 Typical cumulative particle size distribution curve 


\subsection{Optimization model}

The problem is formulated as the sum of sub-activity costs per bench to be removed. The main controllable variable of the optimization model is the mean fragmentation size which can change from a blast to another by drill and blast design. The relationships among the interrelated mining activities lead to a bathtub curve relation between the total mining cost and rock fragmentation as seen in Fig. 4. The shaded area in this figure represents the minimum total mining cost and corresponding optimum mean fragmentation size. Finding this area is formulated as an optimization problem.
The formulation of the optimization problem is defined below.

Objective function

Minimize $C_{M}=C_{D}+C_{B}+C_{L}+C_{H}+C_{C}$

where

$C_{D}=\frac{\left(H+0.3 \times\left(0.03780 \times D \times\left(\frac{\rho_{e}}{\rho_{r}}\right)^{0.333}\right)\right) \times N}{r_{D}} * c_{D}$

$$
\left.\begin{array}{l}
C_{B}=\frac{115 \times A^{30 / 19} \times\left[\left(0.03780 \times D \times\left(\frac{\rho_{e}}{\rho_{r}}\right)^{0.333}\right) \times(0.125 \times H+0.875 \times B) \times H\right]^{24 / 19}}{\left(P_{50}\right)^{30 / 19} \times S_{e}} \times p_{e} \times N \\
C_{L}=\frac{\left[\left(0.03780 \times D \times\left(\frac{\rho_{e}}{\rho_{r}}\right)^{0.333}\right) \times(0.125 \times H+0.875 \times B) \times H\right] \times N}{V_{S} \times F\left(P_{50}\right)} \times t_{l} \times c_{L} \\
C_{H}=\frac{\left[\left(0.03780 \times D \times\left(\frac{\rho_{e}}{\rho_{r}}\right)^{0.333}\right) \times(0.125 \times H+0.875 \times B) \times H\right] \times N}{V_{T} \times F\left(P_{50}\right)} \times t_{c} \times c_{T} \\
C_{C}=K_{2} \times M_{i c} \times 4 \times\left(75,000^{-295.075)}-\left(1-e^{-\ln (2)\left(\frac{80}{P_{50}}\right)^{n}}\right)^{-\left({ }^{295+\frac{1-e}{-\ln (2)}\left(\frac{80}{P_{50}}\right)^{n}}\right)}\right) \times u \times V_{0} \times N \times \rho_{r}
\end{array}\right) \times
$$

\subsubsection{Problem formulation}

The total mining cost is minimized by changing two controllable parameters which are the blasthole diameter and mean fragmentation size. The problem is a non-linear problem and hard to solve through an exact method. Therefore, a meta-heuristics, evolutionary algorithm (EA), is selected to solve the model. (Sauvageau and Kumral 2016). A metaheuristic like the EA has two drawbacks: (1) it does not guarantee the optimality, and (2) the EAspecific parameters (e.g., crossover and mutation rates) are selected arbitrarily. However, if the solution space is searched sufficiently, the solution can approach the optimality. Regarding the parameter selection, employing different parameter configurations can also reduce the uncertainty associated with the EA's parameters.
Subject to

(1) The hole diameter should be equal to one of the drill bit size specified in the industrial standards (Sandvik 2015) as given in Eq. (25).

$\boldsymbol{D} \in\{159,171,187,200,216,229,251,270,311$, $349,381,406\}$

(2) The weight of the load should not pass the payload capacity for both shovel and load as given in Eqs. (26) and (27).

$$
\begin{aligned}
& V_{S} \times F\left(P_{50}\right) \times \rho_{r} \leq T_{S} \\
& V_{T} \times F\left(P_{50}\right) \times \rho_{r} \leq T_{T}
\end{aligned}
$$

(3) The maximum particle size should be smaller than the maximum allowable feed size of crusher as given in Eq. (28). 


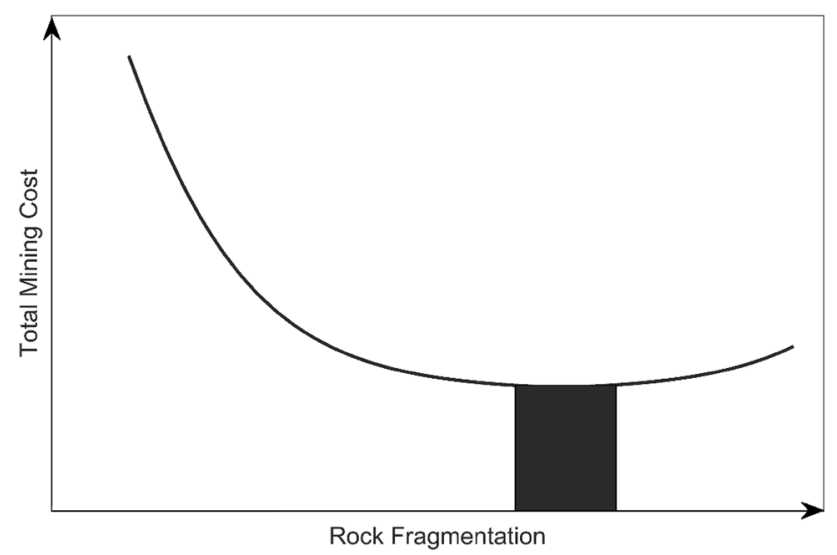

Fig. 4 The relationship between total mining cost and the rock fragmentation

$$
P_{\mathrm{MAX}} \leq R
$$

The model was solved by Excel Solver. The workflow of the evolutionary algorithm used in this research is given in Fig. 5. The input parameters are initially entered into the system. The first population is generated, and the fitness of the population is evaluated. If the stopping criterion is met, the optimization process is terminated and this solution is reported as the optimal solution. Otherwise, it continues to search through creating a new population applying crossover and mutation operators. Then, the new population is evaluated. This workflow continues until the stopping criterion met.

The cost calculation can also be done by using other methods such as mixed-integer non-linear algorithm,

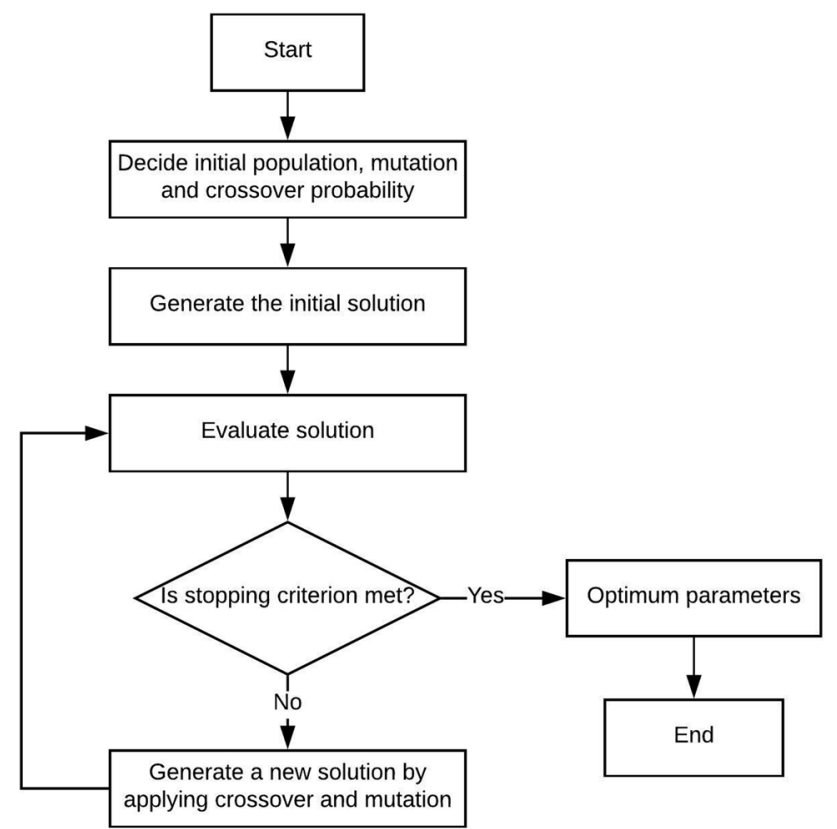

Fig. 5 Flow chart of the proposed evolutionary algorithm simulation-based costing, particle swarm optimization, an artificial neural network, etc. Nolan and Kecojevic (2014) used analytical hierarchy process to improve current mining practices by selecting the optimal mining method based on cost, production and environmental criteria.

\section{Results and discussion}

\subsection{Mine model}

A case study was conducted in an open-cast coal mine. Bench geometry and rock characteristics parameters of the mine are given in Table 1.

Regression analysis of the field data unveiled the relation between the fill factor and mean fragmentation size as given in Eq. (29).

$F\left(P_{50}\right)=0.9833-0.0022 \times P_{50}$

The $R^{2}$ and standard error of the regression are $89.2 \%$ and 0.032 , respectively. This shows that the fill factor equation is representative for this specific mining operation. This information is used in the optimization model.

Table 2 denotes the characteristics of the mining equipment. Since the effect of fragmentation size on the costs is investigated, the costs related to the equipment's

Table 1 Bench geometry and rock characteristics

\begin{tabular}{ll}
\hline Parameter & Value \\
\hline Rock factor, $A$ & 10 \\
Blast geometry constant, $n$ & 1.3 \\
Explosive price $(\$ / \mathrm{kg})$ & 2.5 \\
The bulk density of the explosive (tonne $\left./ \mathrm{m}^{3}\right)$ & 0.82 \\
Length of the bench $(\mathrm{m})$ & 150 \\
The width of the bench $(\mathrm{m})$ & 50 \\
The height of the bench $(\mathrm{m})$ & 10 \\
The bulk density of the rock (tonne $\left./ \mathrm{m}^{3}\right)$ & 2.7 \\
\hline
\end{tabular}

Table 2 Characteristics of mining equipment

\begin{tabular}{ll}
\hline Characteristic & Value \\
\hline Drill rate $(\mathrm{m} / \mathrm{h})$ & 25 \\
Shovel bucket capacity $\left(\mathrm{m}^{3}\right)$ & 27.5 \\
Shovel bucket capacity (tonne) & 90 \\
Loading time (minutes) & 0.5 \\
Truck capacity $\left(\mathrm{m}^{3}\right)$ & 130 \\
Truck capacity (tonne) & 320 \\
Truck cycle time (min) & 15 \\
\hline
\end{tabular}


Table 3 The operation cost of mining equipment (CostMine 2016)

\begin{tabular}{lc}
\hline Equipment & Operation cost $(\$ / \mathrm{h})$ \\
\hline Drilling machine $\left(c_{D}\right)$ & 99.69 \\
Loader $\left(c_{L}\right)$ & 360.63 \\
Haul truck $\left(c_{T}\right)$ & 498.79 \\
\hline
\end{tabular}

Table 4 Parameters of the crushing operation

\begin{tabular}{ll}
\hline Parameter & Value \\
\hline $80 \%$ passing size of crusher feed, $x_{1}(\mu \mathrm{m})$ & $1,389,406$ \\
$80 \%$ passing size of crusher product, $x_{2}(\mu \mathrm{m})$ & 75,000 \\
Crushing work index, $M_{i c}$ & 7.2 \\
Crusher constant, $K_{2}$ & 1.19 \\
Energy price, $u(\$ / \mathrm{kWh})$ & 0.072 \\
\hline
\end{tabular}

part wear and other fixed costs were ignored. Shovel bucket and truck payload capacity were considered as constraints in the optimization model. If bulk density of the loaded material is too high, it is not possible to utilize all volume of the shovel or truck even though particle size is small. In that case, the particle size could be large. The optimum fragmentation size and hole diameter are decided by using abovementioned methodology.

The operations costs for the mining equipment were obtained from CostMine (2016), and they are given in Table 3. These costs are likely to change depending on operational conditions. They should be updated during the operation for more accurate results.

The parameters of crushing operation and crushing cost calculation are given in Table $4.80 \%$ passing size of the crusher feed is calculated from Eq. (17) and energy price is taken from CostMine (2016).

\subsection{Cost optimization}

Once the mine model is formed and all the parameters are connected to each other, evolutionary algorithm was implemented by Excel $^{\circledR}$ Solver. Before starting to optimization, mean fragmentation size and the hole diameter are taken as $50 \mathrm{~cm}$ and $159 \mathrm{~mm}$, respectively. The total mining cost is calculated $\$ 158,311$ for the bench with the initial values. The solver engine divided the problem to 13,341 subproblems and reached to the minimum total mining cost in $43.9 \mathrm{~s}$ by changing these two variables while considering the constraints. The minimum total mining cost to extract given bench is obtained as \$131,670. So, the total mining cost is reduced by $16.8 \%$. To achieve this cost minimization, the mean fragmentation size and the
Table 5 Optimization results

\begin{tabular}{lc}
\hline Parameter & Optimum value \\
\hline Mean fragmentation size, $P_{50}(\mathrm{~cm})$ & 68 \\
Hole diameter $(\mathrm{mm})$ & 200 \\
$P_{80}(\mathrm{~cm})$ & 130 \\
Amount of required explosive $(\mathrm{kg} / \mathrm{hole})$ & 60 \\
Total mining cost $(\$)$ & 131,670 \\
Blasting cost $(\$)$ & 35,297 \\
Drilling cost $(\$)$ & 9391 \\
Loading cost $(\$)$ & 8649 \\
Hauling cost $(\$)$ & 75,941 \\
Crushing cost $(\$)$ & 6907 \\
\hline
\end{tabular}

hole diameter should be $68 \mathrm{~cm}$ and $200 \mathrm{~mm}$, respectively. The other results of the optimization are given in Table 5 .

\subsection{Sensitivity analysis}

The previous sections describe how to calculate the cost of the activities and optimization of total cost in a mining operation. However, some of these costs may change during the operation depending on equipment reliability, human performance, and seasonal effect, etc. For example, the explosive and electricity price, the hourly unit cost of drilling machine, loader and truck may vary in different mine or change during the operation. To quantify the effect of variation of these costs on the total mining cost, sensitivity analysis is conducted. Sensitivity analysis is a technique to quantify the relative importance of different independent parameters on a dependent output variable (Saltelli et al. 2000). In the mining industry, it was used to understand the effect of road length, diesel price and electrical price on the capital and operational expenditures (Dilhuydy et al. 2017). Moreover, de Werk et al. (2017) applied sensitivity analysis to evaluate the parameters of two different material haulage methods as in-pit crushing and conveying systems and traditional truck-shovel system. Furthermore, a sensitivity analysis was used to quantify the impact of the purchase price, operating and maintenance cost of the drilling machine (Al-Chalabi et al. 2015).

The results of sensitivity analysis are summarized in Fig. 6. As can be seen from the figure, the mining cost highly depends on the unit cost of trucks. The reason behind this is that the truck usage time is longer than the other equipment because of the longer cycle time. A $10 \%$ increase in the unit cost of trucks leads to $\$ 7382$ increase in total mining cost. The explosive price also has a considerable effect on the total mining cost. The total mining cost increases $\$ 2736$ if explosive price increases $10 \%$. Moreover, electricity price affects the crushing cost. If electricity 


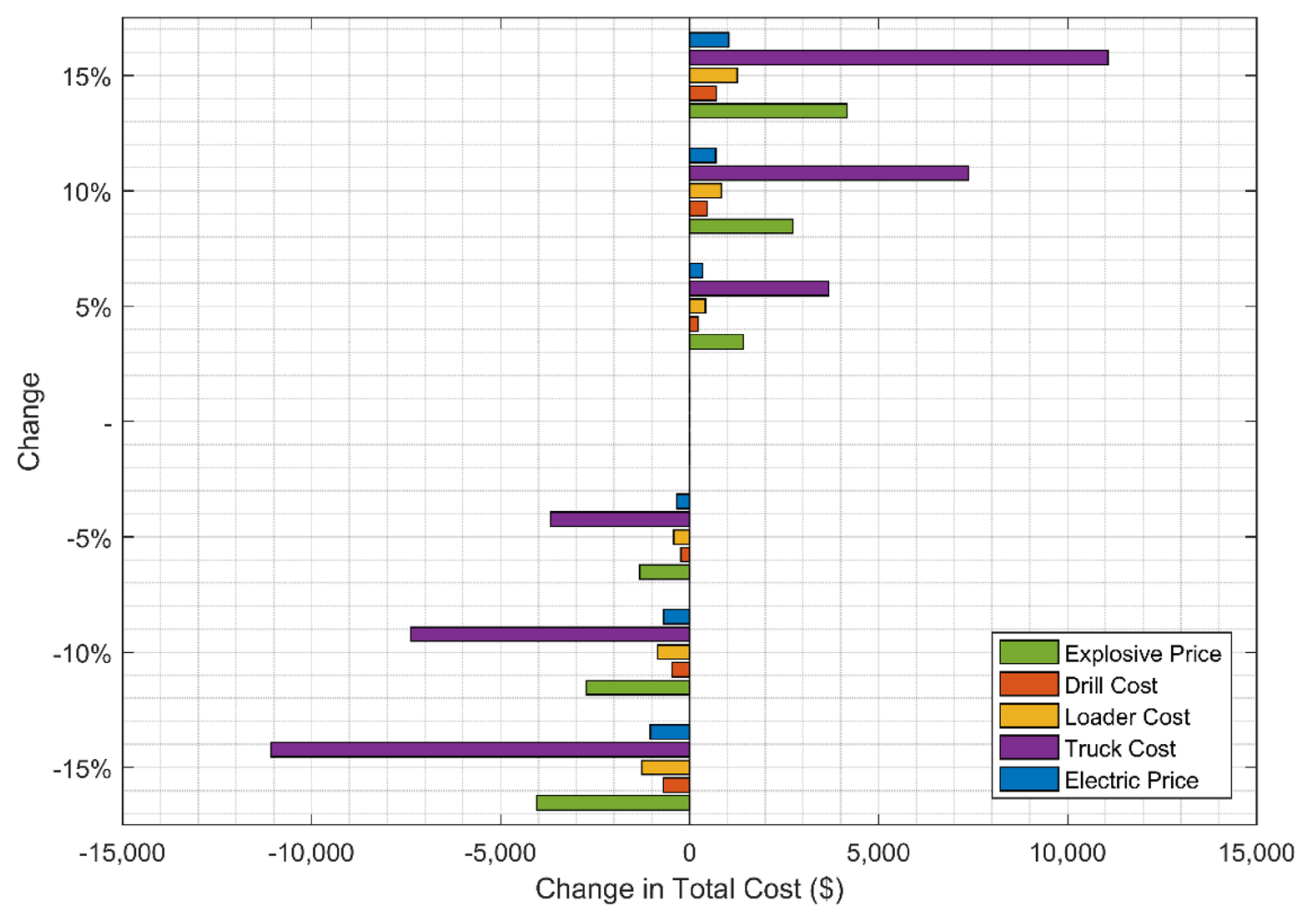

Fig. 6 Sensitivity analysis

price change $15 \%$, the total cost change about $\$ 1036$. On the other hand, the unit cost of drilling machine and loader does not have a significant impact on the total mining cost. If the unit cost of drilling machine and loader change $10 \%$, the total mining cost changes $\$ 463$ and $\$ 841$, respectively.

\section{Conclusions}

This paper presents a system-wide cost optimization approach to minimize the operational cost of open-cast mining operations by analyzing the relationship among the mining subsystems including drilling, blasting, loading, hauling and crushing. The particle size of the blasted muck pile is the common cost parameter for all activities. Thus, the cost calculations are based on the mean fragmentation size which is decided by the blast design parameters such as burden, spacing, sub-drill, the explosive charge, etc. Lowering the particle size causes an increase in the drilling and blasting costs. On the other hand, it provides more efficient loading, hauling and crushing till a certain size. Mean particle size affects the loading and hauling by the fill factor. Moreover, the energy requirement of the crushers is directly related to the crusher feed size. When these relations between the mean fragmentation size and the cost of mining activities are considered, optimizing the mean fragmentation size can provide substantial cost savings in mining operations.
The optimization is achieved by considering the entire mining system instead of focusing on a single subsystem. By this way, the relationship among the interrelated subsystems in open-cast mining operations is considered in the optimization model. The methodology was applied in an open-cast coal mine. The evolutionary algorithm was used in the optimization of the fragmentation size and hole diameter. The results of the case study show that the total mining cost is reduced $\$ 26,641$ for the bench which corresponds a $16.8 \%$ decrease for one mining bench. If the usage of this methodology is extended to the other blasting benches throughout the mine, the total gain increases. Furthermore, the results of the sensitivity analysis show that the total mining cost highly depends on the unit cost of haul trucks, explosive cost and electricity price. The unit cost of loaders and drilling machines does not have a significant effect on the total mining cost.

The proposed approach optimizes the cost of a bench production based on given geometric parameters which are defined by considering technical feasibility and safety. In the future, the research will be extended such that more specific constraints (e.g., dust, noise, geotechnical and equipment restrictions) are incorporated into the model. Also, the uncertainties associated with the parameter values will be considered to assess the risk on the decision-making process.

Acknowledgements The authors thank Natural Sciences and Engineering Research Council of Canada (NSERC) for funding this research (ID: NSERC 236482). 
Open Access This article is distributed under the terms of the Creative Commons Attribution 4.0 International License (http://crea tivecommons.org/licenses/by/4.0/), which permits unrestricted use, distribution, and reproduction in any medium, provided you give appropriate credit to the original author(s) and the source, provide a link to the Creative Commons license, and indicate if changes were made.

\section{References}

Al-Chalabi H, Lundberg J, Ahmadi A, Jonsson A (2015) Case study: model for economic lifetime of drilling machines in the Swedish mining industry. Eng Econ 60(2):138-154

AminShokravi A, Eskandar H, Derakhsh AM, Rad HN, Ghanadi A (2017) The potential application of particle swarm optimization algorithm for forecasting the air-overpressure induced by mine blasting. Eng Comput 1:1-9. https://doi.org/10.1007/s00366017-0539-5

Bogunovic D, Kecojevic V (2011) Impact of bucket fill factor. Min Eng 63(8):48-53

Cho SH, Nishi M, Yamamoto M, Kaneko K (2003) Fragment size distribution in blasting. Mater Trans 44(5):951-956

Chugh YP, Behum PT (2014) Coal waste management practices in the USA: an overview. Int J Coal Sci Technol 1(2):163-176. https://doi.org/10.1007/s40789-014-0023-4

CostMine (2016) Mine and mill equipment costs. InfoMine USA, Inc., Spokane Valley

de Werk M, Ozdemir B, Ragoub B, Dunbrack T, Kumral M (2017) Cost analysis of material handling systems in open pit mining: case study on an iron ore prefeasibility study. Eng Econ 62(4):1-18

Dickerson AW, Alexander RB, Hollis AJ (1986) Measurement of payloads carried by mine haul trucks and the influence of payloads on production rates and material movement costs. Paper presented at the Symposia Series-Australasian Institute of Mining and Metallurgy

Dilhuydy E, Ozdemir B, Kumral M (2017) Economic analysis of waste crushing in semi-mobile in-pit crushing and conveying systems. CIM J. https://doi.org/10.15834/cimj.2017.14

Faramarzi F, Mansouri H, Ebrahimi Farsangi MA (2013) A rock engineering systems based model to predict rock fragmentation by blasting. Int J Rock Mech Min Sci 60(Supplement C):82-94. https://doi.org/10.1016/j.ijrmms.2012.12.045

Fisonga M, García YD, Besa B (2017) Burden estimation using relative bulk strength of explosive substances. Appl Earth Sci 126(1):31-37. https://doi.org/10.1080/03717453.2017.1296673

Gheibie S, Aghababaei H, Hoseinie S, Pourrahimian Y (2009) Modified Kuz-Ram fragmentation model and its use at the Sungun Copper Mine. Int J Rock Mech Min Sci 46(6):967-973

Kahriman A, Ceylanoalu A (1996) Blast design and optimization studies for a celestite open-pit mine in Turkey. Mineral Resour Eng 5(2):93-106. https://doi.org/10.1142/S095060989600008X

Kecojevic V, Komljenovic D (2007) Impact of burden and spacing on fragment size distribution and total cost in quarry mining. Trans Soc Min Metall Explor 320:133

Konya CJ (1983) Blast design. In: Sendlein LVA, Yazicigil H, Carlson CL (eds) Surface mining environmental monitoring and reclamation handbook. Elsevier, New York

Kozan E, Liu SQ (2017) An operational-level multi-stage mine production timetabling model for optimally synchronising drilling, blasting and excavating operations. Int J Min Reclam Environ 31(7):457-474. https://doi.org/10.1080/17480930.2016. 1160818

Kulatilake P, Qiong W, Hudaverdi T, Kuzu C (2010) Mean particle size prediction in rock blast fragmentation using neural networks. Eng Geol 114(3):298-311

Kuznetsov V (1973) The mean diameter of the fragments formed by blasting rock. J Min Sci 9(2):144-148

Martin PL (2006) Drill and blast optimization at the Sparkhule Limestone Quarry. J Explos Eng 23(4):6-12

Monjezi M, Khoshalan HA, Varjani AY (2011) Optimization of open pit blast parameters using genetic algorithm. Int J Rock Mech Min Sci 48(5):864-869

Morin MA, Ficarazzo F (2006) Monte Carlo simulation as a tool to predict blasting fragmentation based on the Kuz-Ram model. Comput Geosci 32(3):352-359. https://doi.org/10.1016/j.cageo. 2005.06.022

Morrell S (2009) Predicting the overall specific energy requirement of crushing, high pressure grinding roll and tumbling mill circuits. Miner Eng 22(6):544-549

Neale AM (2010) Blast optimization at Kriel Colliery. J South Afr Inst Min Metall 110(4):161-168

Nielsen K (1983) Optimisation of open pit bench blasting. Paper presented at the 1st international symposium on rock fragmentation by blasting, Lulea, Sweden

Nolan TA, Kecojevic V (2014) Selection of overburden surface mining method in West Virginia by analytical hierarchy process. Int J Coal Sci Technol 1(3):306-314. https://doi.org/10.1007/ s40789-014-0019-0

Osanloo M, Hekmat A (2005) Prediction of shovel productivity in the Gol-e-Gohar iron mine. J Min Sci 41(2):177-184

Ouchterlony F, Sanchidrián JA, Moser P (2017) Percentile fragment size predictions for blasted rock and the fragmentation-energy fan. Rock Mech Rock Eng 50(4):751-779

Pothina R, Kecojevic V, Klima MS, Komljenovic D (2007) Gyratory crusher model and impact parameters related to energy consumption. Miner Metall Process 24(3):170-180

Saltelli A, Chan K, Scott EM (2000) Sensitivity analysis, vol 1. Wiley, New York

Sandvik (2015) Rotary drilling bits and drill string tools

Sauvageau M, Kumral M (2016) Genetic algorithms for the optimisation of the Schwartz-Smith two-factor model: a case study on a copper deposit. Int J Min Reclam Environ. https://doi.org/10. 1080/17480930.2016.1260858

Singh S, Narendrula R (2006) Factors affecting the productivity of loaders in surface mines. Int $\mathrm{J}$ Min Reclam Environ 20(01):20-32

Singh P, Roy M, Paswan R, Sarim M, Kumar S, Jha RR (2016) Rock fragmentation control in opencast blasting. J Rock Mech Geotech Eng 8(2):225-237

Taherkhani H, Doostmohammadi R (2015) Transportation costs: a tool for evaluating the effect of rock mass mechanical parameters on blasting results in open pit mining. J Min Sci 51(4):730-742

Vesilind PA (1980) The Rosin-Rammler particle size distribution. Resour Recov Conserv 5(3):275-277

Workman L, Eloranta J (2003) The effects of blasting on crushing and grinding efficiency and energy consumption. In: Proc 29th Con Explosives and Blasting Techniques, Int Society of Explosive Engineers, Cleveland OH, pp 1-5 